ReFerences

'World Health Organization (1984) Effects of Nuclear War on Health and Health Services. Geneva: WHO.

${ }^{2}$ Thompson, J. A. (1985) Psychological Aspects of Nuclear War. Chichester: John Wiley; and the British Psychological Society.

${ }^{3}$ British Medical Association BoArd of ScIence AND Education (1983) The Medical Effects of Nuclear War. Chichester: John Wiley.

^HACHIY, M. (1955) Hiroshima Diary. Tokyo: Asahi Shimbunsha. solantaus, T., Chivian, E., Vartanyan, M. \& Chivian, S. (eds.) (1985) Impact of the Threat of Nuclear War on Children and Adolescents. Boston: International Physicians for the Prevention of Nuclear War.

${ }^{6}$ DYER, J. (1985) Co-operation not confrontation: the imperative of a nuclear age. British Medical Journal, 291, 191-193.

'McCally, M., Dienstbier, Z., Jansen A., Juvonen, J., Nicolopoulou-Stamat,, P. \& Rappaport, R. (1985). An international survey of medical school programmes on nuclear war. Medical Education, 19, 364-367.

\title{
Education Act 1981
}

\section{The first year of working as reported by consultants in child and adolescent psychiatry}

Christopher Wardee, Consultant in Child and Adolescent Psychiatry, Dryden Clinics for Children and Adolescents, Wonford, Exeter

The Education Act (1981) was brought into effect on 1 September 1983. Explanatory and guidance documents were published in 1983.1.2 The Education Act has effects on the work of child and adolescent psychiatrists in two ways. Firstly it affects those in-patient and day units that have education on the premises. Secondly it affects the placement of children who have special educational needs because of emotional or behavioural problems, the children who in the past would have been deemed maladjusted. While child psychiatrists should be involved in all cases where emotional and behavioural problems are the main issue, they will also be involved with some of the children who have special educational needs because of intellectual and learning difficulties, children who in the past were deemed educationally subnormal. These children between them constitute a high proportion of those who will, under the new Act, be subjects of statements of need.

It was for this reason that the implementation of the Educational Act was discussed in the Bulletin ${ }^{3}$ and it was decided to monitor the effects of the Act on the work of child and adolescent psychiatrists during the first year after its implementation. The following is a brief report of the survey which was carried out.

At the beginning of the year all regional representatives were asked, through the consultants in their region, to keep a note of the effect of the Act in their clinical work. At the end of the school year the regional representatives were asked to report on the following questions:

(i) What has been the effect of the procedure on parents' co-operation and subsequent work with clinicians?

(ii) Has the receipt of the official letters initiating the procedure upset or worried parents or children?

(iii) Have the new procedures led to any difficulties about placing children or delayed appropriate placement?

(iv) Have there been any other problems arising from the implementation of the Act? (v) In what ways has the Act facilitated or improved the placement of cases?

(vi) What has proved to be good practice in implementing the Act?

Reports were received from all the regional representatives and in addition $\mathbf{4 0}$ individual letters and comments were received. This report attempts to summarise their observations and wherever appropriate we have quoted verbatim these personal communications. Each individual quoted has been allocated a reference number but it was not thought appropriate to list the individual names in this report.

It would appear that the experience of clinicians has been remarkably uniform. There is universal concern about the cumbersome and rather bureaucratic nature of the procedure, the resulting delays in placement, and the time which has to be taken from practical work by key professionals, particularly educational psychologists, in order to make the statements.

A large number of respondents were concerned that writing reports, which would be seen by parents, would have an adverse effect on both the reports and their relationship with the parents. The alternative view was that the procedure had a positive effect on both report writing and relationships with clients.

Before implementation it was feared that the procedure would cause anxiety and emotional disturbance in children and parents. While cases of this have been noted, in practice this has usually been avoided by skilful introduction and explanation of the procedure.

From the first drafting of the Education Bill doubt has been expressed whether the statement procedure was necessary when all the parties involved were in agreement about the needs of the child and were willing to meet them. This remains a concern. All these controversial issues will be considered in more detail.

No reports were received of any difficulties about the education in in-patient and day units. This was a major 
concern during the drafting of the Act. The lack of difficulties must be the result of the College representations to the Department of Health and Social Security and as a result of the good offices of the DHSS in their discussions with the Department of Education and Science, in particular Section 16 of Circular 1/83 gave valuable guidance. ${ }^{1}$

\section{Delays}

Forty-one respondents specified delay as a problem and there were no reports of improvement in efficiency as a result of the statementing procedure. The delays and cumbersome procedure are found particularly irksome by those who had been used to a flexible informal procedure with close co-operation between the professions and the administration. The following are representative of the views expressed by a very large number of the respondents: '....prior to the act we had a fairly straightforward system of referral and transfer to day special units in Avon'; 'It seems to most of us that the bureaucracy involved in the implementation of the new Act is a hindrance and that the informal procedures used previously facilitated communication and allowed clinicians to handle potentially troublesome issues with patients in a more supportive way'; 'It is rather cumbersome and over bureaucratic formalisation of previous good practice'; 'Delays are causing children to be kept in in-patient units longer than they should have been.'

The procedure can delay very considerably the placement of a child in a special school if the authority insists on waiting for the full process of statementing to be completed before the child is placed. The reports indicate that not all authorities are aware of, or wish to use, the advice in paragraph 16 of Circular 1/83:

Nor are formal procedures required where the need for extra help is of short duration; or where the child is placed by agreement with the parent in a special school or unit for a short period as part of the assessment process; or where the child attends a hospital special school on a temporary basis as a result of having been admitted on medical grounds to the hospital to which that school is attached. They may, however, be needed for longstay patients, for example if they have severe learning difficulties or complex disabilities.

Where this advice has been used it has led to quick and flexible placement. The procedure, if applied inflexibly, not only leads to delay in placement while the child may remain out of school or in an inappropriate school, but can also lead to increasing the length of time children have to remain in a hospital bed.

Clinicians are finding that in order to diminish these delays, they have to spend extra time encouraging administrators and others to hasten the paperwork. The expense and time involved in the statement procedure raises the question whether it need be applied where there is agreement between professionals, administrators and parents about the child's needs and how to meet them: 'We have always had a good working relationship with the psychologists and the education department has quite a good record of discussion with parents. It therefore may seem more frustrating to us to find this system institutionalised, whereas in counties where such involvement with the families was not the norm, clearly the act will have been an advantage'; 'I suppose the act is drawing together the various reports necessary to implement the best educational placement for the child... but...that was happening anyway in clinics where good practice was conducted.'

\section{Reporting}

There appears to be great variation between colleagues in their practice in writing and method of transmitting reports for inclusion in the statement. That parents will see the statement is considered by some as a severe constraint leading to such 'dishonest' or 'restricted' reporting that the reports lead to unsatisfactory decision making:

Parents of children needing special education on emotional grounds are commonly emotionally vulnerable and occasionally overtly paranoid. There are obvious difficulties in preparing a report accessible to such parents which will have sufficient impact to convince the education authority of the severity of the child's difficulties. We failed to get one child placed, largely because of this problem.

A surprisingly large number of professionals and administrators do not appear to have appreciated that the statement should be confined to outlining the child's special educational needs. It should therefore be brief and should only include statements which make quite clear what the child's needs are. The statement is not intended to be a detailed report of the child's mental state, social circumstances, history, etc. The statement is therefore not written for the purpose of informing the staff of the school to which the child is being transferred about his background, diagnosis or treatment. This should be transmitted in the form of a confidential report and would not be seen by parents or anyone other than the person to whom it is addressed.

The purpose of the statement is to make the child's needs plain so that they can be catered for and so that they can be understood and agreed by the parents and the education authority. Where this has been understood, many consultants have found the procedure helpful as a discipline on their reporting and have found that it improves open communication between them and the parents - the following comments were made:

The production of written reports which the parents see has sharpened my practice in producing reports, concentrating on the essential features and clarifying what we expect from the programme.

I quite like the way in which case communication is now open and one has to say things in a way which is acceptable to the family. I find this is good discipline, also my reports are very much shorter.

Statementing has occasionally proved quite useful in getting across to parents why we feel special education is necessary. Some parents have queried what I have written and I have made some changes to please them. The debate has been quite fruitful. 
The whole process is much more open and children and their parents have the opportunity of discussing the recommendations and challenging the reports. This has perhaps made one put rather less into the reports, but on balance it has probably been an advantage.

Circular $1 / 18$ sets out a very simple form for the statement which has been adopted in some districts. The old SE forms are much too detailed and inappropriate to form the statement itself. They include much medical terminology and the 'yes/no' format does not result in information which would be clear to lay people unfamiliar with the form. In any case, to find data one would have to search through the SE form. An adequate statement of a child's educational needs should be possible on one side of foolscap.

An impression seems to have been created that professionals are not allowed to 'name the school which in their opinion would be best suited to an individual child's needs'-Circular $1 / 83$ does seem slightly confusing on this. Section 35 puts some constraint on our freedom to discuss possible schools in so far as we must not 'commit the LEA' or 'pre-empt their decisions'. The instruction that 'professional advice should not be influenced by considerations of the eventual school placement to be made for the child' could be seen as being in conflict with the whole object of the exercise which is stated in Section 45: 'The LEA must describe the type of school they consider appropriate for the child and name the particular school if known.' Some respondents deal with this confusion by separate communication with the educational psychologist or administrator, while others couch their statement of need in such a way that no mistake can be made about which school is appropriate. No objection has been made to the phrase 'provision such as that available at the $\mathrm{X}$ school'.

\section{The effect on educational psychological services}

From every region there were reports of a reduction in the time educational psychologists had to give to work with children in schools and with the child and adolescent psychiatric teams (child guidance teams). This loss of direct patient contact and work with the team may in the long term militate against prevention and supportive work and thus increase the number of children needing special places. Not only this but a reduction in the time and opportunities for consultation may lead to misplacement.

It is very much regretted by many correspondents that this is a further example of the erosion of the joint working which was central to the success of the regional child guidance services. Some clinicians had noted that the delays and the withdrawals of the school psychological support had led some head teachers to use suspension as a tactical move to get children seen.

\section{The efiect of the procedure on parents and children}

The increased participation by parents has been valued by most clinicians and reference was made by some reporters to the benefit of written comments and parents being included in the assessment process and statement.
In the early stages there were reported a number of instances of distress at the formal letter from the LEA. Since then letters appear to have been modified. This does not seem to be appreciated very widely, but is seen by many as demanding the exercise of great sympathy and diplomacy by clinicians, social workers and educational psychologists, which can be seen as an unnecessary and avoidable demand on valuable clinical time. Clinicians' experience of parental reaction to the procedure and on co-operation with the clinic during and following it have varied widely from, 'without exception no ill effects' to 'in some cases considerable misunderstanding and distress' and 'in many, raised anxiety'.

\section{Other problems encountered}

In some LEAs the statementing procedure seems to be considered necessary in order to get special equipment or extra help for children in ordinary schools. This may mean that a child is made the subject of a statement to justify the appointment of a teacher's aide who may help a number of children with similar problems. Since the procedure has profound implications for a child's whole future and is a major matter for his family, there should be a reappraisal of this particular use of the procedure.

It was noted that children had been made subject of statements because of behavioural or emotional problems without an opinion being sought from the child and adolescent psychiatric service. This practice seems counter to the advice in Circular 1/83, paragraphs 29 and 33:

29. Medical advice must be sought from the medical officer designated for this purpose by the district health authority in the terms outlined in paragraph 13 of DHSS Circular HN(82)9. Before submitting his advice, the designated medical officer will co-ordinate information from all the doctors who have a contribution to make to the assessment of the child's special educational needs.

33. The local child, adolescent and family psychiatric services, whether hospital or community based, may be an appropriate source of advice about children with emotional or behavioural problems.

It would seem essential that designated medical officers should be advised that such an opinion be always sought when emotional, behavioural or psychiatric disturbance forms part of the child's problem.

\section{Evaluation appraisal of services}

It was noted by some clinicians that the Act had led to improvement in the evaluation of schools being used, although it was noted with regret that some valued but rather specialised or small schools were encountering difficulty.

A major aim of the Warnock Committee had been to develop a better evaluation of the services which were really needed by children and this did not yet seem to be occurring.

Conclusion

The use of the Act inevitably impinges on the individual 
freedom of the child and his family. It emphasises and labels the separateness of children with special needs permanently and it reduces flexibility of provision. It takes up much valuable professional time and is therefore costly.

Warnock ${ }^{4}$ considered that the acknowledged disadvantages of recording were outweighed by the following advantages: (i) unless needs are recorded there will be defaults in provision; (ii) it ensures continuing specialised help if children move from one school or LEA to another; and (iii) it gives the right to parents to demand that the child's needs are met and to appeal if they are not. We recommend that consideration be given to a less cumbersome and more informal method of recording for all cases where there is agreement between parents, professionals and LEA about the child's needs.

\section{Reperences}

'Department of Education and Sctence (1983) Joint Circular: Assessments and Statements of Special Educational Needs. Circular 1/83.

${ }^{2}$ Department of Health and Soctal Security (1983) Health Circular HC (83)3; Local Authority Circular LAC(83)2.

${ }^{3}$ Royal College of Psychiatrists (1984) Education Act 1981: Monitoring the application of the Education Act 1981 in its first year in operation. Bulletin of the Royal College of Psychiatrists, 8, 13-14.

'The Warnock Report (1978) Special Educational Needs: Report of the Committee of Enquiry into the Education of Handicapped Children and Young People (the Warnock Report). Cmnd 7212. London: HMSO.

\section{Whatever Happened to Stigma?}

T. H. TURNER, Senior Registrar, Department of Psychological Medicine, St Bartholomew's Hospital, London ECl

Even before Erving Goffman's Stigma: Notes on the Management of Spoiled Identity was published in 1963, it had been a commonplace notion that there was a stigma attached to psychiatric illness. King Lear's cry 'Let me not be mad, not mad, sweet heaven' echoes down the ages. But in the years since Goffman's book there has been a concerted attempt by psychiatrists, by patients' groups, by the media, to 'destigmatise' and 'demythologise' psychiatry. This has taken many subtle forms, but several major themes were apparent.

One school felt that the labelling of an individual, as a schizophrenic for example, tended to promote a persistent handicap and should therefore be avoided, particularly in young people. But the substitution of terms such as 'situational crisis in a vulnerable individual' or 'schizoid personality' or 'adjustment reaction' did not actually make nuclear symptoms go away. Such euphemisms may even have led to inadequate treatment and a reinforcement of the belief that psychiatric illness was untreatable. Nor is it entirely clear why the term 'schizophrenia' should have had a more noxious, stigmatising effect than the terms 'multiple sclerosis' or 'diabetes mellitus'. It seems to have been a conceit of psychiatrists that the general public, many of whom are ignorant of where their liver is, should somehow know all about the severe effects of a true schizophrenic illness. Nevertheless, at least the real issue behind this concern, misdiagnosis, has been systematically tackled. Improved training, operational criteria for diagnosis, and the WHO studies have all helped, while it is probably true that the vagueness and variability of psychiatrists in describing psychopathology is in thankful decline.

Other attempts to destigmatise have involved the transfer of psychiatric facilities to general hospital premises. Thus out-patient and in-patient care can now be equated with medical treatment and plans to phase out the large asylums continue apace. It is difficult to gauge how successful this has been.
Some psychiatrists clearly welcome no longer being isolated from their professional colleagues. Whether these same professional colleagues welcome psychiatrists and their patients wandering around the general hospitals is less clear. 'Liaison psychiatry' has an enthusiastic priesthood, but seems to be viewed by some physicians primarily as a means of disposing of their difficult or uncooperative patients. Perhaps it is fortunate that the modern fashion of medicalising one's distress by taking an overdose has made psychiatric involvement something of a necessity on the acute medical wards. But this very fashion of overdosing, of seeking white-coated hospital care, may well derive in part from the public's anxiety about direct psychiatric referral. It is because of the persistence of stigma that we, the psychiatrists, have had to follow our patients into the general hospitals? Are we merely reinforcing the stigma by camouflaging ourselves as humdrum hospital doctors?

Alongside this professional sidestep has been the growth of care in the community, a contentious issue often seen in black or white terms. While deinstitutionalisation was the main thrust behind this policy, there was also a belief that the stigma of mental illness would be reduced by the presence of psychiatrically handicapped individuals living normally and safely in the house next door. Provided these clients/patients-should we name them according to medical or social terminology?-are well behaved, such community care may be successfully destigmatising. But the increase in vagrancy, the much-publicised pressures on the prison system, the occasional episode of psychotic violence (e.g. the ex-Broadmoor patient who stabbed someone at random so as to return to an institution) may well be reinforcing the old, primal prejudices. Psychiatrists trying to establish medium secure units have also met powerful local resistance of the NIMBY (Not In My Back Yard) variety.

Nevertheless, outside the profession as well there have been important initiatives. The work of MIND in establishing patients' rights, the changes in the 1983 